\title{
Desigualdades raciais no Brasil: síntese de indicadores e desafios no campo das políticas públicas
}

\author{
Racial inequalities in Brazil: a synthesis of social \\ indicators and challenges for public policies
}

Rosana Heringer 1

1 Centro de Estudos
Afro-Brasileiros, Instituto
de Humanidades,
Universidade Cândido
Mendes. Praça Pio X 7,
7 o andar, Rio de Janeiro, RJ
$20040-020$, Brasil.
heringer@candidomendes.edu.br

\begin{abstract}
This article aims to systematize and analyze social data that reveal the dimension of racial inequalities in Brazil. The point of departure is that racial inequalities affect the capacity for integration of Blacks into Brazilian society and jeopardize the proposal to build a democratic society with equal opportunities for all. Such inequalities are present at different moments in the individual life cycle, beginning in childhood and continuing through school years, in access to urban infrastructure, and crystallizing in the labor market, consequently determining the income and living conditions of Afro-Brazilians as a whole. The article also analyzes the main positions in the political debate on racial inequalities in Brazil, identifying recent initiatives by both the Brazilian government and civil society to deal with racial discrimination and racial inequalities. The article concludes by identifying key challenges for health policy-makers in this context.
\end{abstract}

Key words Blacks; Racial Discrimination; Racial Inequality; Public Policy; Social Indicators

Resumo Este artigo pretende sistematizar e analisar indicadores que revelam a dimensão das desigualdades raciais no Brasil. Parte-se do princípio de que as desigualdades raciais, ao afetarem a capacidade de inserção dos negros na sociedade brasileira, comprometem o projeto de construção de um país democrático e com oportunidades iguais para todos. Essas desigualdades estão presentes em diferentes momentos do ciclo de vida do indivíduo, desde a infância, passando pelo acesso à educação, à infra-estrutura urbana e cristalizando-se no mercado de trabalho e, por conseqüência, no valor dos rendimentos obtidos e nas condições de vida como um todo. Também serão apresentadas as principais vertentes do atual debate político sobre desigualdades raciais no Brasil, identificando as iniciativas por parte do Estado brasileiro e da sociedade civil destinadas a enfrentar a discriminação e as desigualdades raciais. Finalmente, pretende-se apontar alguns desafios colocados para os formuladores de políticas de saúde a partir deste quadro.

Palavras-chave Negros; Discriminação Racial; Desigualdade Social; Política Social; Indicadores Sociais 


\section{Introdução}

O Brasil encontra-se entre as maiores economias do mundo e foi considerado, ao longo de várias décadas, o país da "democracia racial". Entretanto, embora nunca tenha se consolidado no país um regime de segregação racial legal e formal, a realidade brasileira é outra. As distinções e desigualdades raciais são contundentes, facilmente visíveis e de graves conseqüências para a população afro-brasileira e para o país como um todo. A literatura é pródiga em trabalhos que demonstram, ao longo de décadas, a presença e a persistência das desigualdades raciais a da situação subalterna do negro na sociedade brasileira (Fernandes, 1978; Guimarães, 1999, 2002; Hasenbalg \& Silva, 1988, 1992, 1999).

Este artigo pretende sistematizar e analisar indicadores que revelam a dimensão das desigualdades raciais no Brasil. Também serão apresentadas as principais vertentes do atual debate político sobre desigualdades raciais no Brasil, identificando as iniciativas por parte do Estado brasileiro e da sociedade civil destinadas a enfrentar a discriminação e as desigualdades raciais. Finalmente, pretende-se apontar alguns desafios colocados para os formuladores de políticas de saúde a partir deste quadro, bem como serão identificadas algumas lacunas de conhecimento e necessidades de investigação neste campo de intervenção e avaliação de políticas públicas.

As informações apresentadas praticamente falam por si mesmas. As desigualdades são graves e, ao afetarem a capacidade de inserção dos negros na sociedade brasileira, comprometem o projeto de construção de um país democrático e com oportunidades iguais para todos. Apresentam-se em diferentes momentos do ciclo de vida do indivíduo, desde a saúde na infância, passando pelo acesso à educação e cristalizando-se no mercado de trabalho e, por conseqüência, no valor dos rendimentos obtidos e nas condições de vida como um todo. Está presente na diferença entre brancos e negros em termos de acesso à justiça. Esperamos que as informações e análises aqui contidas sirvam de subsídio para uma reflexão profunda sobre as desigualdades raciais no Brasil, levando à sugestão e à adoção de medidas que venham a beneficiar, em curto prazo, a população negra do Brasil.

\section{Contextualização histórica e distribuição da população por cor}

O Brasil foi o último país do mundo a abolir o trabalho escravo de pessoas de origem africana, em 1888, após ter recebido, ao longo de mais de três séculos, cerca de quatro milhões de africanos como escravos (Heringer et al., 1989; IBGE, 1987). Embora nenhuma forma de segregação tenha sido imposta após a abolição, os ex-escravos tornaram-se, de maneira geral, marginalizados em relação ao sistema econômico vigente. Além disso, o governo brasileiro iniciou, na segunda metade do século XIX, o estímulo à imigração européia, numa tentativa explícita de "branquear" a população nacional. Milhões de imigrantes europeus entraram no país durante as últimas décadas do século XIX e no início do século XX. Essa força de trabalho foi contratada preferencialmente tanto na agricultura como na indústria que estava sendo implantada nas principais cidades.

Durante a década de 1930, quando o país iniciava sua industrialização e, ao mesmo tempo, seus intelectuais debatiam em torno da definição de uma identidade nacional, havia uma interpretação que ganhou força no meio intelectual brasileiro, que assinalava " $a$ idéia de que o Brasil era uma sociedade sem 'linha de cor', ou seja, uma sociedade sem barreiras legais que impedissem a ascensão social de pessoas de cor a cargos oficiais ou a posições de riqueza e prestígio" (Guimarães, 2002:139), sintetizada na concepção de uma democracia racial. A origem precisa desta expressão não está totalmente esclarecida. Como afirma Guimarães (2002: 139), "na literatura acadêmica especializada, o uso primeiro parece caber a Charles Wagley: 'O Brasil é renomado mundialmente por sua democracia racial', escrevia Wagley, em 1952...". No lugar de nos envergonharmos de nossa maioria negra e mestiça, devíamos nos orgulhar e admirar isto como um sinal de nossa tolerância e integração racial. Afinal, nós não possuíamos uma segregação legal como nos Estados Unidos e na África do Sul e éramos capazes de conviver bem com todas as raças. Depois da Segunda Guerra Mundial, a Organização das Nações Unidas para a Educação, Ciência e Cultura (UNESCO) financiou um extenso projeto de pesquisa sobre o Brasil. Segundo Maio (1999:143-144), “a 'opção Brasil' guarda íntima relação com o contexto internacional da época. (...) A controvertida crença numa democracia racial à brasileira, que teve no sociólogo Gilberto Freyre a mais refinada interpretação, tornou-se assim um dos principais alicerces ideológicos da integração racial e do desenvol- 
vimento do país e foi suficientemente substantiva para atrair a atenção internacional".

O Projeto Unesco constituiu-se num importante marco do estudo sobre relações raciais no Brasil e no processo de institucionalização das Ciências Sociais de uma forma geral. Alguns autores afirmam que o Projeto Unesco frustrou suas expectativas iniciais ao ter identificado o preconceito racial persistente no país, que era com freqüência descrito como "paraíso racial" (Skidmore, 1976; Winant, 1994). Maio (1999), entretanto, afirma que embora houvesse por parte da Unesco "uma imagem positiva do país em matéria racial”, o projeto "desenvolveu-se de forma mais complexa", resultando numa visão mais contrastante do cenário racial brasileiro. Maio (1999:151) reproduz uma declaração do principal idealizador do Projeto Unesco, Alfred Métraux, na qual ele considera o Brasil "um exemplo de país onde as relações entre as raças são relativamente harmoniosas, todavia registra que 'seria uma exagero [...] afirmar que o preconceito racial é ignorado".

Durante os anos 60 e 70, a ditadura militar suprimiu muitas formas de liberdade intelectual e atividade política, dificultando a organização dos movimentos sociais e, entre eles, do movimento negro. Isto não impediu, porém, que florescessem várias formas de resistência cultural negra, principalmente nos grandes centros urbanos. O Censo Nacional de 1970 não incluiu o quesito sobre raça ou cor em seus formulários. No fim dos anos 70, uma variedade de movimentos sociais começou a se reorganizar, buscando melhorar as condições sociais do país (Hanchard, 2001). Entre eles, grupos referidos genericamente como Movimento Negro estavam decididos a combater a discriminação racial no Brasil. O primeiro governo civil foi eleito indiretamente em 1985. Os anos 80 foram marcados por importantes avanços, em termos de democratização política, culminando com a promulgação de uma nova Constituição em 1988.

Neste período, estudiosos começaram, mais uma vez, a examinar a "questão racial”, contribuindo para a construção de uma rede composta por intelectuais, ativistas e agências de cooperação internacional que favoreceram a inserção da questão racial na agenda pública nacional (Bourdieu \& Wacquant, 2002). Militantes denunciaram as desigualdades raciais e tentavam entender por que o mito da democracia racial ainda estava vivo e era aceito de maneira geral. Em um país com enormes desigualdades sócio-econômicas, era difícil para os negros compreender que suas condições de vida precárias eram resultantes também da dis- criminação racial. Isto começou a mudar devido à crescente visibilidade de um ativo Movimento Negro, à presença de um pequeno grupo de intelectuais negros e de artistas que freqüentemente levantavam o assunto e, também, à intenção governamental de fazer algo em relação ao assunto, criando agências específicas para cuidar da cultura negra, da situação dos descendentes dos antigos escravos e da legislação anti-racista.

\section{Critérios de classificação racial}

O censo brasileiro pede às pessoas que se classifiquem dentro de uma das cinco categorias seguintes: branco, preto, pardo, indígena ou amarelo (oriental). Pretos e pardos constituem $45 \%$ de toda população e $98.7 \%$ da população não-branca (IBGE, 1996).

No Brasil, o conceito de raça encontra-se mais relacionado à cor da pele e traços faciais do que à ancestralidade. Isso levou alguns estudiosos a analisar a classificação racial brasileira não enquanto grupos raciais, mas sim grupos de cor (Degler, 1991).

Outra característica da classificação brasileira se relaciona ao nosso passado e ao mito da democracia racial. Como Guimarães explica: " a especificidade do racismo brasileiro, ou do racismo latino-americano em geral, vem do fato de que a nacionalidade brasileira não fo $i$ formada, ou 'imaginada', para usar a metáfora de Anderson, como uma comunidade de indivíduos etnicamente dissimilares, vindos de todas as partes da Europa, como ocorreu nos EUA. O Brasil é um amálgama de mestiços de diferentes origens raciais e étnicas, cuja raça e etnicidade foram perdidas, a fim de ganhar a nacionalidade brasileira" (Guimarães, 1995:215).

Para propósitos estatísticos, considerandose que a flexibilidade da classificação de cor no Brasil torna difícil diferenciar ambos os grupos, e também a proximidade em termos de indicadores sócio-econômicos entre os dois grupos, pesquisadores como Nelson do Valle Silva e Carlos Hasenbalg, seguidos por vários outros, consideram geralmente pretos e pardos juntos, como uma única categoria. Assume-se que a maioria dos pardos possui ascendência africana. Neste texto, as palavras negros e afro-brasileiros são usadas alternadamente, significando aqueles que se classificam como pretos e pardos nas pesquisas do IBGE.

A partir dos dados mais recentes disponíveis na Tabela 1 , podemos observar que a população brasileira compõe-se de $54 \%$ de brancos e $45,3 \%$ de negros, segundo a auto-declaração dos informantes. A distribuição regional 
apresenta-se bastante diferenciada, com grande concentração da população afro-brasileira nas regiões Nordeste e Norte. O sul do país possui população majoritariamente branca e a Região Centro-Oeste apresenta uma distribuição equilibrada entre brancos e negros, similar à distribuição nacional.

\section{Infra-estrutura urbana e habitação}

É de conhecimento geral a estreita relação entre as condições de saúde e o acesso à infra-estrutura básica em termos de serviços públicos, tais como saneamento, coleta de lixo e acesso à eletricidade, entre outros. Os dados disponíveis na Tabela 2, para 1999, revelam que brancos e negros no Brasil têm um acesso desigual a estes serviços.

Outros indicadores de condições de vida e acesso a serviços disponíveis para o ano de 1999, citados por Henriques (2001), revelam mais aspectos da desigualdade entre negros e brancos no que diz respeito à infra-estrutura urbana. Ainda que este quadro tenha melhorado para o conjunto do país ao longo da década, as diferenças entre negros e brancos permanecem, conforme pudemos ver anteriormente. Segundo o IBGE (1999), 15,2\% dos brancos vivem em domicílios sem coleta de lixo, enquanto 30,3\% dos negros encontram-se nesta situação.

Analisando este e outros indicadores habitacionais numa série histórica (1992-1999), Henriques (2001:18), afirma que os dados indicam "uma trajetória de aumento das diferenças entre brancos e negros, sobretudo nos indicadores de acesso à coleta de lixo, escoamento sanitário, acesso à energia elétrica e abastecimento de água".

Baseados nesses e em outros dados, os pesquisadores Wânia Sant'Anna \& Marcelo Paixão (1997), utilizaram o Índice de Desenvolvimento Humano (IDH), usado pelo Programa das Nações Unidas para o Desenvolvimento (PNUD), para calcular a qualidade de vida relativa da população afro-brasileira (pretos e pardos). O IDH do conjunto da população brasileira era de 0,796 (para um máximo de 1,000). Para os afro-brasileiros, o IDH era 0,573.

"O IDH para os afro-brasileiros é pior do que o dos países latino-americanos, exceto Nicarágua, que vem logo atrás com 0,568. (...) Uma triste situação para o paraíso da democracia racial..." (Sant'Anna \& Paixão, 1997:33).

\section{Acesso à educação}

O acesso à educação é geralmente apresentado pelos estudiosos como um dos principais fatores associados ao alcance de melhores oportunidades no mercado de trabalho e, conseqüentemente, um melhor rendimento. Para um grande contingente da população, o aumento da escolaridade é visto como o principal caminho de mobilidade social ascendente dos indivíduos. Diante deste quadro, ganha ainda mais importância a análise das oportunidades educacionais de brancos e negros no Brasil, e, principalmente, sobre a relação entre este desempenho e a alocação dos dois grupos no mercado de trabalho, como veremos mais adiante.

Uma primeira constatação é a baixa escolaridade da população brasileira como um todo, já que a média do país é de apenas 5,7 anos de estudo. Supondo que não haja repetência, isto equivaleria apenas à conclusão da $5 \underline{a}$ série do ensino básico. Um outro aspecto a se levar em conta é a diferença em termos de anos de estudo entre negros e brancos. Estes últimos possuem em média dois anos de estudo a mais do que os negros.

A Tabela 3 demonstra não a média, mas os anos de estudo efetivamente cursados pelas pessoas de 15 anos ou mais. Em primeiro lugar, se comparamos a situação de 1988 e 1996 verificamos que houve um aumento da escolaridade dos brasileiros no período. Entretanto, esta ampliação do acesso à escola não se traduziu numa diminuição das desigualdades raciais, já que a proporção de negros entre as pessoas com 12 anos ou mais de estudo (equivalente aos que concluíram o ensino médio e possuem curso superior) é de apenas $2,8 \%$, quase quatro vezes menos do que os brancos na mesma faixa $(10,9 \%)$. Por outro lado, a proporção de negros entre aqueles sem instrução ou com menos de um ano de estudo continua em 1996 a ser mais do dobro da proporção de brancos nesta faixa.

A permanência deste padrão de desigualdade educacional entre negros e brancos encontra-se igualmente explicitada no trabalho realizado por Ricardo Henriques (2001:27), onde ele demonstra que "um jovem branco de 25 anos tem, em média, mais 2,3 anos de estudo que um jovem negro da mesma idade, e essa intensidade da discriminação racial é a mesma vivida pelos pais desses jovens - e a mesma observada entre seus avós. (...) A escolaridade média de ambas as raças cresce ao longo do século, mas o padrão de discriminação racial, expresso pelo diferencial nos anos de escolaridade entre brancos e negros [2,3 anos em média], mantémse absolutamente estável entre as gerações". 
Este quadro geral da situação educacional dos negros no Brasil, representa uma das principais dificuldades a serem enfrentadas a fim de gerar maior igualdade de oportunidades entre brancos e negros no país. Atenta a este cenário, a presidente do Instituto Nacional de Estudos e Pesquisas Educacionais (INEP), ligado ao Ministério da Educação, afirmou em artigo recente que a população negra continua apresentando um nível de escolaridade mais baixo. Esta é uma das prioridades para uma política de eqüidade e integração socioeconômicas que requer uma ação mais afirmativa do poder público e da sociedade (Castro, 1998).

\section{Mercado de trabalho e distribuição de renda}

“Mais de um século depois da abolição da escravidão, o trabalho manual continua a ser o lugar reservado para os afro-brasileiros. Em oposição ao que afirmaram as teorias sobre modernização, a estrutura de transição fornecida pelo rápido crescimento econômico nas últimas décadas não parece ter contribuído para diminuir de maneira significativa a distância existente entre os grupos raciais presentes na população" (Hasenbalg, 1996:15).

Os negros brasileiros têm feito pouco progresso na conquista de profissões de maior prestígio social, no estabelecimento de seus próprios negócios e na ocupação de posições de poder político. Eles ainda concentram-se em atividades manuais que exigem pouca qualificação e escolaridade formal. As desvantagens acumuladas através da história brasileira tornaram o sucesso difícil para a população afrobrasileira (Lima, 1999).
Tabela 1

Distribuição da população por cor ou raça*, 1999.

\begin{tabular}{|c|c|c|c|c|}
\hline & \multicolumn{4}{|c|}{$\%$} \\
\hline & Branca & Preta & Parda & $\begin{array}{l}\text { Amarela e } \\
\text { indígena**}\end{array}$ \\
\hline Brasil & 54,0 & 5,4 & 39,9 & 0,6 \\
\hline 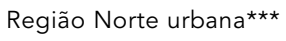 & 28,4 & 2,3 & 68,3 & 1,0 \\
\hline Região Nordeste & 29,7 & 5,6 & 64,5 & 0,2 \\
\hline Região Sudeste & 64,0 & 6,7 & 28,4 & 0,8 \\
\hline Região Sul & 83,6 & 3,0 & 12,6 & 0,7 \\
\hline Região Centro-Oeste & 46,2 & 3,5 & 49,4 & 0,8 \\
\hline
\end{tabular}

Fonte: Pesquisa Nacional por Amostra de Domicílios (IBGE, 2000).

* exclusive as pessoas que não declararam sua cor.

** o dado disponível na Síntese de Indicadores Sociais não desagregou estas duas categorias (nota da autora).

*** exclusive a população da área rural de Rondônia, Acre, Amazonas, Roraima, Pará e Amapá.

Tabela 2

Domicílios por condição de saneamento segundo a cor do chefe, 1999.

\begin{tabular}{|c|c|c|c|c|}
\hline & \multicolumn{4}{|c|}{$\%$} \\
\hline & \multicolumn{2}{|c|}{$\begin{array}{l}\text { Água canalizada e rede } \\
\text { geral de distribuição }\end{array}$} & \multicolumn{2}{|c|}{ Esgoto e fossa séptica } \\
\hline & Branca & Preta e parda & Branca & Preta e parda \\
\hline Brasil & 82,8 & 67,2 & 62,7 & 39,6 \\
\hline Região Norte urbana* & 68,6 & 57,5 & 19,2 & 12,7 \\
\hline Região Nordeste & 66,7 & 55,1 & 28,7 & 19,8 \\
\hline Região Sudeste & 90,0 & 82,5 & 83,9 & 71,0 \\
\hline Região Sul & 79,8 & 77,3 & 46,4 & 34,0 \\
\hline Região Centro-Oeste & 75,2 & 66,4 & 38,7 & 31,3 \\
\hline
\end{tabular}

Fonte: Pesquisa Nacional por Amostra de Domicílios (IBGE, 2000).

* exclusive a população da área rural de Rondônia, Acre, Amazonas, Roraima, Pará e Amapá.

\begin{tabular}{|c|c|c|c|c|c|c|c|c|}
\hline \multirow[t]{3}{*}{ Anos de estudos } & \multicolumn{4}{|c|}{1988} & \multicolumn{4}{|c|}{1996} \\
\hline & \multicolumn{3}{|c|}{ Cor } & \multirow[t]{2}{*}{ Total } & \multicolumn{3}{|c|}{ Cor } & \multirow{2}{*}{ Total } \\
\hline & Brancos & Pretos & Pardos & & Brancos & Pretos & Pardos & \\
\hline $\begin{array}{l}\text { Sem instrução/ } \\
\text { Menos de } 1 \text { ano }\end{array}$ & 17,9 & 34,5 & 34,2 & 24,9 & 11,8 & 26,2 & 23,4 & 16,7 \\
\hline $1-3$ anos & 22,3 & 26,9 & 27,0 & 24,3 & 13,3 & 18,5 & 19,5 & 15,9 \\
\hline 4-8 anos & 40,0 & 31,4 & 29,8 & 35,5 & 43,8 & 41,3 & 40,7 & 42,4 \\
\hline 9-11 anos & 12,6 & 5,9 & 7,3 & 10,3 & 20,3 & 11,2 & 13,3 & 17,2 \\
\hline 12 anos e + & 7,3 & 1,2 & 1,6 & 4,9 & 10,9 & 2,4 & 2,8 & 7,5 \\
\hline Sem declaração & - & - & - & - & 0,3 & 0,3 & 0,3 & 0,3 \\
\hline
\end{tabular}

Fonte: Hasenbalg \& Silva (1999). 
Informações recentes, obtidas a partir de pesquisa específica realizada em seis regiões metropolitanas do país, indicam que a desigualdade racial está presente nos mais variados indicadores associados ao desempenho de brancos e negros no mercado de trabalho. Na Região Metropolitana de São Paulo, a maior cidade brasileira, a taxa de desemprego entre os homens negros é de $20,9 \%$, enquanto esta taxa é de 13,8\% entre os brancos (INSPIR/DIEESE/ AFL-CIO, 1999). O valor do salário médio diário de negros e brancos também revela grandes disparidades. Em São Paulo, os negros ganham em média $\mathrm{R} \$ 2,94$ por dia, enquanto os brancos recebem R\$5,50 (INSPIR/DIEESE/AFL-CIO, 1999).

Como afirma o relatório sobre desigualdades raciais no mercado de trabalho, "é preciso que o Estado invista em políticas públicas e implemente de fato a Convenção 111 da OIT, invertendo a lógica da estrutura de oportunidades, que está profundamente marcada por práticas violadoras de direitos e de discriminações baseadas na raça e no sexo" (INSPIR/DIEESE/ AFL-CIO, 1999:8). A pesquisa revela que apenas $1,9 \%$ dos negros ocupados em São Paulo são empregadores, em comparação aos 7,2\% de brancos nesta posição, enquanto mais da metade das mulheres negras (56,3\%) estão ocupadas como domésticas ou mensalistas (INSPIR/ DIEESE/AFL-CIO, 1999).

$\mathrm{O}$ quadro de desigualdade entre negros e brancos está relacionado tanto a fatores estruturais quanto à discriminação. Entre os fatores estruturais, sem dúvida o mais significativo é o componente educacional. Ao se situarem nos grupos com menor acesso à educação formal, os negros também ocupam postos de menor prestígio no mercado de trabalho. A Tabela 4 demonstra que, enquanto $32,8 \%$ dos brancos ocupados na Região Metropolitana de São Paulo possuem grau de escolaridade até o lograu incompleto (ensino fundamental), cerca de $54 \%$ dos negros estão nesta posição. A situação se inverte quando analisamos a faixa equivalente ao ensino médio e ao ensino superior. Neste último grupo a proporção de brancos equivale a quase cinco vezes a dos negros.

No que diz respeito ao rendimento, negros e brancos também possuem situações desiguais. Ainda no caso da Região Metropolitana de São Paulo, apenas 5,3\% dos negros ocupados recebem mais de 10 salários mínimos.

Esse fato poderia ser interpretado - e em muitos casos o é - como decorrente somente do menor grau de instrução dos negros. Entretanto, mesmo quando se encontram em iguais condições de escolaridade, negros e brancos possuem rendimentos diferenciados. Essa si- tuação se agrava principalmente nos grupos com grau de instrução mais elevado. Tal fato pode ser atribuído à ausência, entre os negros, de redes pessoais que permitam maior acesso a melhores oportunidades de emprego. Também pode ser atribuído à sub-remuneração e à sub-utilização de mão-de-obra negra qualificada, decorrente da discriminação racial.

Este quadro apresentado para a Região Metropolitana de São Paulo não se constitui num caso isolado. Ao contrário, reproduz-se em todo o país, provavelmente de formas mais acentuadas em regiões com menor circulação de riqueza e atividade econômica menos dinâmica.

O perfil de distribuição de renda aqui apresentado é consistente com a composição racial da pobreza, tal como apresentada por Henriques (2001). O autor aponta que, em 1999, os negros constituíam $45 \%$ da população e totalizavam $64 \%$ dos pobres (e $69 \%$ dos indigentes). Inversamente, os brancos eram $54 \%$ da população, e totalizavam apenas $36 \%$ dos pobres e $31 \%$ dos indigentes.

\section{Estratégias de combate às desigualdades raciais no Brasil}

\section{Políticas públicas de combate às desigualdades raciais}

Como resultado das constantes reivindicações do Movimento Negro, o governo brasileiro tem se mostrado mais sensível à questão da discriminação racial no país. No conteúdo do Décimo Relatório Relativo à Convenção Internacional sobre a Eliminação do Todas as Formas de Discriminação Racial (MJ/MRE, 1996), enviado pelo governo brasileiro às Nações Unidas, reconhece-se a existência de práticas discriminatórias que repercutem em todas as instâncias sociais, incluindo-se aí desde relações interpessoais até indicadores de qualidade de vida da população. Apesar do racismo ser definido como crime (Lei n. 7.716 de 5 de janeiro de 1989), persiste uma relação causal entre cor e desigualdades.

No âmbito governamental, porém, as iniciativas de combate às desigualdades raciais ainda têm um alcance limitado e podem ser mais facilmente identificadas nos documentos e recomendações do que por meio de ações práticas. O Programa Nacional de Direitos Humanos (MJ, 1998), por exemplo, dedica uma seção inteira à apresentação de propostas relacionadas ao tema das desigualdades raciais, resultantes em grande medida dos trabalhos do GTI (Grupo de Trabalho Interministerial para Valo- 
Distribuição dos ocupados por nível de instrução segundo raça e sexo. Região Metropolitana de São Paulo, 1998.

\begin{tabular}{|c|c|c|c|c|c|c|c|c|c|}
\hline \multirow[t]{3}{*}{ Nível de instrução } & \multicolumn{6}{|c|}{ Raça } & \multicolumn{3}{|c|}{ Total } \\
\hline & \multicolumn{3}{|c|}{ Negra1 } & \multicolumn{3}{|c|}{ Não-negra1 } & & & \\
\hline & Homens & Mulheres & Total & Homens & Mulheres & Total & Homens & Mulheres & Total \\
\hline Analfabeto & 5,9 & 6,0 & 6,0 & 2,8 & 2,5 & 2,7 & 3,7 & 3,6 & 3,7 \\
\hline 1ㅇ Grau incompleto & 56,7 & 50,4 & 54,0 & 35,4 & 29,0 & 32,8 & 41,8 & 35,8 & 39,3 \\
\hline 1ㅇ Grau completo & 13,6 & 12,8 & 13,3 & 12,5 & 10,4 & 11,7 & 12,9 & 11,2 & 12,2 \\
\hline 2o Grau incompleto & 7,1 & 7,5 & 7,3 & 7,4 & 7,2 & 7,3 & 7,3 & 7,3 & 7,3 \\
\hline 2ㅇ Grau completo & 12,2 & 16,6 & 14,1 & 19,4 & 23,5 & 21,1 & 17,2 & 21,3 & 18,9 \\
\hline 3으 Grau & 4,4 & 6,5 & 5,3 & 22,5 & 27,4 & 24,5 & 17,1 & 20,7 & 18,6 \\
\hline Total & 100,0 & 100,0 & 100,0 & 100,0 & 100,0 & 100,0 & 100,0 & 100,0 & 100,0 \\
\hline
\end{tabular}

1 Raça negra = pretos e pardos; raça não-negra = brancos e amarelos

Fonte: Pesquisa de Emprego e Desemprego - Região Metropolitana de São Paulo (Departamento Intersindical de Estatística

e Estudos Sócio-Econômicos/Fundação Sistema Estadual de Análise de Dados) <http://www.dieese.org.br/ped/ped.html>.

rização da População Negra), criado após a mobilização das organizações do movimento negro por ocasião da celebração dos 300 anos de Zumbi dos Palmares, em 1995.

Em julho de 1996, o governo federal organizou a conferência Multiculturalismo e Racismo: O Papel da Ação Afirmativa nos Estados Democráticos Contemporâneos (Grin, 2001). Em seu discurso de abertura, o Presidente Fernando Henrique Cardoso declarou: “Devemos, pois, buscar soluções que não sejam pura e simplesmente a repetição ou a cópia de outras soluções imaginadas para situações em que também há discriminação e o preconceito, mas em contexto diferente do nosso. É melhor, portanto, buscarmos uma solução mais imaginativa" (Souza, 1997:15).

Após a conferência, começaram os trabalhos do GTI, seguindo as recomendações levantadas durante o encontro. Várias medidas propostas envolviam algum tipo de programa de ação afirmativa, que deveria ser desenhado para promover o acesso de mais negros a empregos e educação.

O documento Construindo a Democracia Racial (Presidência da República, 1998:39), apresenta os "planos de ação que estão sendo ou serão desenvolvidos" em termos de políticas públicas. Este documento, juntamente com o Plano Nacional de Direitos Humanos, expressa as diretrizes governamentais para o combate às desigualdades raciais no Brasil.

De maneira geral, acreditamos que o Estado brasileiro, nas suas diversas instâncias, ainda não demonstrou o comprometimento necessário com a diminuição das desigualdades raciais. Mesmo nos programas que já vêm sendo implementados, é possível identificar a in- suficiência de recursos materiais e humanos que garantam o bom andamento dos mesmos. Constata-se, também, a descontinuidade de programas e a falta de sensibilidade de muitos técnicos e funcionários para incorporar o combate às desigualdades e à discriminação racial no seu cotidiano de trabalho.

\section{A sociedade civil e o combate às desigualdades raciais}

Assistimos ao longo dos últimos anos a proliferação de variadas iniciativas relacionadas ao enfrentamento das desigualdades raciais no Brasil. Muitas delas nem sempre utilizam esta terminologia, mas colocam entre seus objetivos a promoção da população afro-brasileira. É difícil enquadrá-las em uma única classificação, dada a diversidade de atividades desenvolvidas.

Na tentativa de agrupá-las, podemos destacar os seguintes tipos de organizações: atividades comunitárias, geralmente em favelas ou bairros de periferia, destinadas à promoção social de crianças e jovens, por meio de reforço escolar, de atividades profissionalizantes e de educação voltadas para o exercício da cidadania; atividades de apoio e estímulo a microempresários afro-brasileiros: esta atividade envolve treinamento em conhecimentos ligados à administração empresarial e qualificação profissional; estímulo e ampliação do acesso de afro-brasileiros ao ensino superior: esta atividade se dá principalmente servindo-se da organização de cursos preparatórios (pré-vestibular) para o exame de admissão às universidades brasileiras (Maggie, 2001).

Estas são, entre outras, algumas das iniciativas que ilustram a existência de uma mobili- 
zação de diferentes setores da sociedade no sentido da adoção de políticas de promoção da igualdade.

O Brasil passou por um grande processo de mudanças ao longo dos últimos anos, no que diz respeito às relações raciais. A percepção do país como uma democracia racial é cada vez menos consensual, e hoje diferentes setores da sociedade têm sua agenda política marcada pelo debate sobre o racismo como elemento constitutivo de nossa sociedade. Embora ainda esteja também presente a auto-imagem do Brasil como um país homogêneo e indiferenciado, encontra-se progressivamente maior abertura a experiências que procuram beneficiar grupos específicos, historicamente com menor acesso a oportunidades. Isso já é uma realidade no que diz respeito a grupos minoritários tais como os portadores de deficiência, idosos, homossexuais, portadores de vírus HIV, e também com relação às mulheres, que ao longo da última década foram capazes de garantir maior acesso a espaços de poder e melhores posições no mercado de trabalho. O quadro ainda não está equilibrado, mas é possível observar um avanço em relação à preocupação em torná-lo mais justo. No que diz respeito às desigualdades advindas das diferenças étnicas e raciais, o quadro apresenta-se mais tímido, porém já podem ser detectadas transformações no que diz respeito a uma maior freqüência e aceitação de programas que procurem atuar neste campo.

Apesar destas e de outras iniciativas, é difícil afirmar que a sociedade brasileira possui um compromisso com a diminuição das desigualdades raciais. A maioria das pessoas simplesmente se recusa a levar raça em conta, quando são consideradas as causas da pobreza e da falta de oportunidades. Entretanto, existe a percepção de que a maioria dos pretos e pardos são pobres, e de que a maioria dos pobres são pretos e pardos. Essa percepção pode transformar-se em um ponto de partida para sugerir a adoção de medidas específicas a alguns grupos.

O debate sobre ação afirmativa no Brasil é bastante recente, datando dos últimos cinco anos (Heringer, 1995). De uma maneira geral, o movimento negro brasileiro tem sido o responsável pela introdução desse tema no debate público do país. Freqüentemente o assunto é alvo de muitas críticas e resistências à sua incorporação. As críticas mais comuns destacam que políticas específicas trariam conflito e divisionismo a um país onde as relações raciais seriam harmônicas. As críticas relacionam-se também à inadequação de políticas deste tipo, uma vez que a situação desvantajosa da popu- lação negra estaria associada ao seu baixo grau de escolaridade. Portanto, uma melhoria geral das políticas educacionais traria os benefícios esperados à população afro-brasileira.

Em pouco mais de dois anos, o quadro passou por grandes transformações. O assunto ganhou importância no debate político no Brasil, especialmente em 2001, devido ao processo preparatório da Conferencia Mundial contra o Racismo (CMR). Além da mobilização do movimento negro, um aspecto importante desse processo foi o posicionamento público de alguns representantes do governo, especialmente do IPEA (Instituto de Pesquisa Econômica Aplicada, vinculado ao Ministério do Planejamento). O IPEA divulgou indicadores que revelaram a dimensão das desigualdades raciais no Brasil (Henriques, 2001). Não se tratava mais de um pequeno grupo de ativistas denunciando a histórica desigualdade de oportunidades entre brancos e negros: o Estado brasileiro adotou um discurso anti-racista, trazendo o tema para o centro da agenda política.

O debate público intensificou-se durante a CMR, quando foi divulgado o relatório oficial do governo brasileiro, incluindo a recomendação da adoção de cotas para estudantes negros nas universidades públicas.

Durante os últimos meses de 2001 e o primeiro semestre de 2002, ainda sob o "calor" dos resultados da conferência de Durban, outros setores do governo federal, alguns governos estaduais e municipais lançaram publicamente programas e ou projetos de lei especificamente destinados a beneficiar os afro-brasileiros.

Um dos principais fatores que influenciarão o sucesso de nossos programas de ação afirmativa, é sem dúvida, a existência de um consenso cada vez maior sobre a necessidade de políticas deste tipo. O compromisso da sociedade (brancos e negros) com a execução destas políticas será proporcional ao sucesso que as mesmas possam vir a ter.

Ao adotar qualquer tipo de programa de ação afirmativa no Brasil, nós devemos evitar a suspeita de padrões reduzidos ao empregar ou selecionar, e buscar um forte apoio da opinião pública. Este não poder ser visto apenas como um "tema negro", mas um meio de se buscar uma sociedade mais justa e igualitária. 


\section{Referências}

BOURDIEU, P. \& WACQUANT, L., 2002. Sobre as artimanhas da razão imperialista. Estudos Afro-Asiáticos, 24:15-34.

CASTRO, M. H. G., 1998. Avaliação do sistema educacional brasileiro: Tendências e perspectivas. Ensaio: Avaliação de Políticas Públicas em Educação, 6:303-364.

DEGLER, C. N., 1991. Neither Black nor White. Madison: University of Wisconsin Press.

FERNANDES, F., 1978. A Integração do Negro na Sociedade de Classes. São Paulo: Ática.

GRIN, M., 2001. Esse ainda obscuro objeto de desejo: Políticas de ação afirmativas e ajustes normativos. O seminário de Brasília. Novos Estudos CEBRAP, 59:172-192.

GUIMARÃES, A. S. A., 1995. Racism and anti-racism in Brazil: A postmodern perspective. In: Racism and Anti-Racism in World Perspective (B. Bowser, ed.), pp. 208-226, London: Sage.

GUIMARÃES, A. S. A., 1999. Racismo e Anti-Racismo no Brasil. São Paulo: Editora 34.

GUIMARÃES, A. S. A., 2002. Classes, Raças e Democracia. São Paulo: Editora 34.

HANCHARD, M., 2001. Orfeu e o Poder: Movimento Negro no Rio de Janeiro e em São Paulo. Rio de Janeiro: EDUERJ.

HASENBALG, C., 1996. Os Números da Cor. Rio de Janeiro: Centro de Estudos Afro-Asiáticos.

HASENBALG, C. \& SILVA, N. V., 1988. Estrutura Social, Mobilidade e Raça. São Paulo: Vértice.

HASENBALG, C. \& SILVA, N. V., 1992. Relações Raciais no Brasil Contemporâneo. Rio de Janeiro: Rio Fundo.

HASENBALG, C. \& SILVA, N. V., 1999. Educação e diferenças raciais na mobilidade ocupacional no Brasil. In: Cor e Estratificação Social (C. Hasenbalg, N. V. Silva \& M. Lima, org.), pp. 217-230, Rio de Janeiro: Contracapa.

HENRIQUES, R., 2001. Desigualdade Racial no Brasil: Evolução das Condições de Vida na Década de 90. Texto para Discussão 807. Rio de Janeiro: Instituto de Pesquisa Econômica Aplicada.

HERINGER, R., 1995. Introduction to the analysis of racism and anti-racism in Brazil. In: Racism and Anti-Racism in World Perspective (B. Bowser, ed.), pp. 203-207, London: Sage.

HERINGER, R. (org.), 1999a. A Cor da Desigualdade: Desigualdades Raciais no Mercado de Trabalho e Ação Afirmativa no Brasil. Rio de Janeiro: Instituto de Estudos Raciais e Étnicos/Instituto de Filosofia e Ciências Sociais, Universidade Federal do Rio de Janeiro.

HERINGER, R., 1999b. Addressing Race Inequalities in Brazil: Lessons from the United States. Working Paper Series 237. Washington, DC: Latin American Program, Woodrow Wilson International Center for Scholars.

HERINGER, R., 2000. Desigualdades Raciais no Brasil. Brasília: Escritório Nacional Zumbi dos Palmares.

HERINGER, R., 2001. Mapeamento de ações e discursos de combate às desigualdades raciais no Brasil. Estudos Afro-Asiáticos, 23:291-334.

HERINGER, R., no prelo. The Challenge of Practice: Affirmative Action and Diversity Programs in Brazil and the U.S. Washington, DC: Woodrow Wilson International Center for Scholars.

HERINGER, R.; SANT'ANNA, W.; MARTINS, S. \& OLIVEIRA, S., 1989. Negros no Brasil: Dados da Realidade. Petrópolis: Editora Vozes/Instituto Brasileiro de Análises Sociais e Econômicas.

IBGE (Fundação Instituto Brasileiro de Geografia e Estatística), 1987. Estatísticas Históricas do Brasil. Rio de Janeiro: IBGE.

IBGE (Fundação Instituto Brasileiro de Geografia e Estatística), 1996. Contagem da População. Rio de Janeiro: IBGE.

IBGE (Fundação Instituto Brasileiro de Geografia e Estatística), 1999. Pesquisa Nacional por Amostra de Domicílio 1999: Síntese dos Indicadores Sociais. <http://www.ibge.gov.br>.

INSPIR (Instituto Sindical Interamericano pela Igualdade Racial) /DIEESE (Departamento Intersindical de Estatística e Estudos Socioeconômicos)/ AFL-CIO (American Federation of Labor and Congress of Industrial Organization), 1999. Mapa da População Negra no Mercado de Trabalho. São Paulo: INSPIR.

LIMA, M., 1999. O quadro atual das desigualdades. In: Cor e Estratificação Social (C. Hasenbalg, N. V. Silva \& M. Lima, org.), pp. 231-240, Rio de Janeiro: Contracapa.

MAGGIE, Y., 2001. Os novos bacharéis: A experiência do pré-vestibular para negros e carentes. Novos Estudos CEBRAP, 59:193-202.

MAIO, M. C., 1999. O Projeto Unesco e a agenda das ciências sociais no Brasil dos anos 40 e 50. Revista Brasileira de Ciências Sociais, 14:141-158.

MJ (Ministério da Justiça), 1998. Programa Nacional de Direitos Humanos. Brasília: Secretaria Nacional dos Direitos Humanos, MJ.

MJ (Ministério da Justiça) / MRE (Ministério das Relações Exteriores), 1996. Décimo Relatório Periódico Relativo à Convenção Internacional sobre a Eliminação de Todas as Formas de Discriminação Racial. Brasília: FUNAG/MJ.

PRESIDÊNCIA DA REPÚBLICA, 1998. Construindo $a$ Democracia Racial. Brasília: Presidência da República.

SANT'ANNA, W. \& PAIXÃO, M., 1997. Desenvolvimento humano e população afrodescendente no Brasil: Uma questão de raça. Proposta, 73:20-37.

SKIDMORE, T., 1976. Preto no Branco: Raça e Nacionalidade no Pensamento Brasileiro. São Paulo: Paz e Terra.

SOUZA, J. (org.), 1997. Multiculturalismo e Racismo: Uma Comparação Brasil-Estados Unidos. Brasília: Paralelo 15.

WINANT, H., 1994. Racial Conditions: Politics, Theory, Comparisons. Minneapolis: University of Minnesota Press.

Recebido em 24 de abril de 2002

Versão final reapresentada em 10 de outubro de 2002 Aprovado em 30 de outubro de 2002 